\author{
Margareth de Almeida Gonçalves \\ Universidade Federal Rural do Rio de J aneiro
}

\title{
Artifício e excesso: namativa de viagem e a visão sobre as mulheres em Portugal e Brasil
}

\begin{abstract}
Resumo: Este artigo a nalisa as imagens de mulheres brasileiras e portuguesas construídas nos relatos de viajantes ingleses que estiveram em Portugal e no Brasil, nos anos finais do século XVIII e nas primeiras décadas do século XIX. Procura-se explorar como um registro moral, que acentuava crescentemente padrões de comportamento burgueses e que orientou o olhar de viajantes sobre o mundo, interferiu nos comentários e ima gens que projetara $m$ do universo lusobra sileiro. A c onexã o entre o mund o europeu 'c iviliza do' e as regiões marg ina is a o processo de constituição de uma ordem burguesa ca pita lista rea liza da pelos viajantes envolveu, em geral, um duplo processo de enfrentamento e negociação entre valores e concepções de mundo de universos cultura is distintos. Assim, os relatos dos viajantes mostram esse espaço de constante remanejamento de sentimentos e de percepções sobre si próprios e os nativos.
\end{abstract}

Palavras-chave: livros de viagem, gênero, privado-públic o, educação.

Copyright $\odot 2005$ by Revista Estudos Feministas

${ }^{1}$ Este artigo está inserido no programa de pesquisa intitulado "Civilização e a rtifício: modernidade e educação no Brasil do século XIX", que recebeu apoio do CNPq.

2 Aqui, o processo civilizador refere-se às mudanças a pontadas por Norbert Elias para o caso europeu tanto no plano da constituição e consolidaçãa 0 da unidade política do Estado, quanto na dimensão do indivíduo, a través do crescente controle e disciplinarização dos afetos, das emoções e dos comportamentos (ELAS, 1990, p. 216).
Os relatos de viajantes sobre Brasil e Portugal modelaram um padrão uniforme de perfis e imagens de comportamentos, hábitos e costumes, oferecendo uma taxonomia da vida social luso-bra sileira. Este artigo procura fixar-se nas imagens que compõem a concepção dos viaja ntes so bre o universo portug uêse brasileiro de mulheres dos setores médios e altos nas primeiras déc a das do século $\mathrm{XIX}{ }^{1}$

Antes, porém, de avançarmos, convém uma breve introdução sobre a posição dos viajantes oitocentistas, a ssina lando o lugarde onde fala $m$, no sentido de precisar um delineamento de uma estrutura de mentalidades e de atitudes que regeu a maneira de olhar povos de lugares percebidos como estranhos a o mundo europeu, de uma Europa a lém Pirinéus, nã o ibérica. Na posição de repórterjornalista os viajantes deixaram relatos minuciosos sobre povos que percebiam à margem da matriz civilizatória ${ }^{2}$ 
${ }^{3}$ Walter BENJ AMIN, 1993, p. 199.

\begin{abstract}
${ }^{4}$ As formas de narrativa épica caracterizam-se pela concisão enqua nto o rela to de informação jornalística singulariza-se pelo abuso de detalhes, de explicações. "Masa informação a spira a uma verific ação imediata. Antes de mais nada, ela precisa sercompreensível 'em si e para si'. Muitas vezes não é ma is exa ta que os rela tos a ntigos. Porém, enquanto esses relatos recorriam freqüentemente ao miraculoso, é ind ispensável que a informação seja plausível. Nisso ela é incompatível com o espírito de narrativa. Se a arte da na rrativa é hoje rara, a difusão da informação é decisivamente responsável por esse declínio" (BENJ AMIN, 1993, p. 203).

${ }^{5}$ Mary PRATT, 1999, p. 197

${ }^{6}$ Lily UTVAK, 1987, p. 14.

7 O confronto entre matrizes de visões de mundo distintas tem sido destacado por vasta bibliografia sobre os viajantes (Luiz Costa LIMA, 1989; Flora SÜSSEKIND, 1990; Maria Helena ROUANET, 1991; Ma ry PRATT, 1999; e Luciana de Lima MARTINS 2001).

8 Margareth de Almeida GONÇALVES, 2003.
\end{abstract}

européia. Assim, os livros de via gem do séc ulo XIX recheiamse de explic ações sobre o que é visto no sentido de fomecer garantias de autenticida de a o texto. E é nesse sentido que a escrita desse na rrador-viajante a proxima-se do joma lístico, nessa compulsão pela informação. Esse escritor-viajante distingue-se do narrador dos livros de viagem do século $\mathrm{XVI}$, como Jean de Lery, que, em perspectiva distinta, recorriam ao fantástico na busca de sentido para o que viam. Da mesma forma que o romance, também esse modelo oitocentista da literatura de viagem confirmou a propagação da cultura burguesa do livro. A consolidação do capita lismo intro duziu uma nova forma de comunic ação atra vés da informação, que diluiu as formas narrativas épicas plasmadas no miraculoso e no extraordinário. ${ }^{3} 0$ livro de viagem oitocentista é a rea lização de um indivíduo solitário, que reforça no seu rela to a auto-reflexão psicológica, num movimento sem fim do sujeito à procura de uma verdade sobre si, que rompe com asformasépicas de narraçã o. ${ }^{4} \mathrm{~A}$ difusão do livro e da imprensa transformou 0 a to de leitura num prazer único e pessoal, reafirmando na dimensão do sujeito um movimento infindável de autodescoberta e de afirmação da individualidade. E se firmava, então, um pacto entre na rrador e leitor na incomensurável busca de fruição na sacralização da existência.

A disseminação dos livros de viagens foi concomitante às transformações econômicas na Europa que consolidaram a ordem burguesa e o avanço do capita.$^{5}$ Os diversos rela tos ma nifesta $\mathrm{m}$ o espírito c ientífic 0 presente nesse viajante observador que recorre ao vocabulário classificador e técnico da ciência para a compressão de novas formas de organização social e de cultura. ${ }^{6}$ Um registro moral, que acentua padrões de comportamento burgueses, orientou o olhar de viajantes sobre 0 mundo, ${ }^{7}$ e não só interferiu nos comentários e imagens que construíram, como também, a tra vés de suas trajetórias exemplares, propôs um guia de civilidade, paradigma de comportamento no mundo novo da modemidade capitalista. ${ }^{8}$

Nas zonas de contac to, recorrendo à expressão de Mary Pratt, a dominação e a desigualdade passaram por renegociações e rearranjos, forjando descrições que expressaram o confronto com a alteridade. Os rela tos de viajantes expressam a fronteira de constante remanejamento de sentimentos e de percepções sobre si próprios e os nativos. Na teia discursiva recalcitram as tensões e os conflitos que despontavam da experiência com o outro. Por ma is que viajantes tenham conforma do manifestações de um pa drão civiliza tório burguês, a via gem 
${ }^{9}$ Ariès faz menção a um registro de solidariedade no qual a comunida de envolve o indivíduo, e que organizou as mentalidades na medievalidade e no início da época modema, séculos XVI $\mathrm{XVII}$, mantendo-se posteriomente como expressão de sociabilidade entre as camadas populares. Assim, para 0 autor, nas solida riedades a nônimas, "a comunidade que enquadra e limita o indivíduo - a comunidade rural, a cidadezinha ou o bairro constitui um meio fa miliarem que todo mundo se conhece e se vigia" (ARIĖS, 1991, p. 7-8).

${ }_{10}$ Uma cultura popularde rua, do riso e da ga lhardia soltos, foi uma característica particular do Ocidente medieval analisada por Mikhail BAKHTIN, 1999, e que pode ser estendida para outras modalidades de organização da solid a rieda de coletiva em formas de dominações tradiciona is.

11 "Respecting the manners of the inhabitants of $\mathrm{O}$ Porto, my short residence in this city has enabled me to form but a superficial idea, especia lly of the females, who are seldom observed out of doors except in going to, or retuming from churc $h$, a place they usually visit twice a day; and then the face is veiled, or half-concealed beneath the folds of a black mantle" (MURPHY, 1795, p.15). Murphy, entre as gravuras de seu livro, retrata uma imagem de reclusão e religiosidade da mulher portuguesa, a qual é representada de cabeça coberta, portando entre as mãos um terço. correspondeu a uma esfera de suspensão que auxiliou a reelaborar códigos cultura is.

\section{1 - Reclusão}

A imagem da mulher luso-brasileira encerrada em casa é recalcitrante nos rela tos de viajantes. Essa foi uma das representações sobre a mulher oitocentista fixa da por viajantes que permaneceu para a posteridade e que remete, entretanto, pa ra distintas concepções de privado e público $O$ privado europeu dos séculos XVIII e XIX diferenciava-se da domesticidade luso-brasileira. Caso se procure articular as categorias de privado e público na matriz luso-brasileira, desponta uma dimensão do priva do extremamente dilatada, a qual incluía um uso pessoal da esfera pública, centrada no pater familias. Assim, privado e público tenderam a confluir, indicando uma tendência menor à diferenciação. Esse quadro destaca uma moda lidade de sociabilida de que Philipe Ariès denominou de anônima, em que o indivíduo possui uma posição que se confunde com a comunidade à qual pertence. Nesse tipo de sociabilidade, ${ }^{9}$ as noções de privado e público misturam-se. É um mundo nem privado nem público. A dimensão do público articula-se a uma idéia de rua que é percebida como perigosa e desprotegida. Essa separação casa-proteção/rua-perigo implic ou experiências distintas de sociabilidade. O convívio social restrito à casa patria rcal, um universo partilhado por crianças, adultos, criados e escravos, pareceu sempre estranho e desconfortável a estrang eiros - uma dimensão de solida rieda de coletiva que incorporava ainda a rua através do regozijo e da festa. ${ }^{10}$ observam-se, portanto, dois usos ambíguos, embora complementares, do espaço público, tanto o de lugar de perigo qua nto o de local de congraça mento, da galhardia e do riso solto.

James Murphy, um inglês que esteve em Portugal em fins do século XVIII, teceu alguns comentá rios sobre a sociabilidade da mulher portuguesa. Destaca em sua narrativa que a igreja marcou um dos poucos lugares em que as mulheres era $m$ vista s em públic $0 .{ }^{11}$ No entanto, essa dimensão da rua, compreendida pelo deslocamento à igreja, é percebida por Murphy mais como uma extensão do espaço da casa. Essa marca foi reproduzida pelas distintas narrativas de viajantes. Daí que, embora as idas de mulheres a igreja e cerimonias religiosas fossem constantes, quase diárias, como os próprios relatos de viajantes indicam, a escrita teima em destacar a ausência de mulheresfora dosespaços da casa. Miriam Moreira Leite a ponta esse estereótipo da mulher enclausurada presente 
12 "Estas transcrições de textos sobre os costumes das bra sileiras, ao lado das transcrições anteriores, permitem desd obrara a nálise de dois estereótipos sobre a vida da mulher, no século passado - a reclusão e a relig io sida de" (LEITE, 1979, p. 30) 13 "Os viajantes interp reta vam a ausência de mulheres dasclasse dominantes como um sintoma de costumes patria rcais, de serralho oriental" (DIAS, 1984, p. 68). Os estudos de Eni de Mesquita Sa ma ra desta cam, a inda, o "mito da mulher submissa e do marido dominador" como um dos estereótipos das imagens da mulher dos setores dominantes. Sobre os viajantes comenta: "os relatos dos viajantes que percorreram várias partes do Bra sil trouxera m uma visã o parcia da situa ção da mulher na família e na sociedade, mas souberam enfatizar a sua opressão" (SAMARA, 1998, p. 58). no ima giná rio dos viajantes que estiveram no Brasil. ${ }^{12}$ Ma ria Odila Dias menciona o "mito da dona ausente" como organizador da estrutura de interpretação dos livros de viajantes. ${ }^{13} \mathrm{O}$ isolamento da mulher foi uma peça central de um manual que viajantes já decoravam antes da chegada a regiões que, como as regiões portuguesa e brasileira, estavam na periferia ou fora do diapasão c apitalista. Nota-se, portanto, uma distinta apreensão das noções de privado e público para portugueses, brasileiros e viajantes.

A percepção de viajantes das esferas privada e pública foi conduzida pelo processo de constituição de uma ordem burguesa no Ocidente que paulatinamente se diferenciava da matriz social que formou a medievalidade. o privado europeu organizou-se em descontinuidade e tensão com a concepção da domestic ida de luso-brasileira. A dimensão da intimidade na matriz burguesa encontra-se subordinada à mais profunda privacidade, na qual se realiza a construção de sujeitos, com a demarcação de uma identidade pessoal, única e singular. Sempre que os sina is de intimidade, como a exibição do corpo nu e a sexualidade, são exibidos em público produzem desconforto e crítica.

Nos diferentes rela tos de viajantes, mesmo o tipo de sociabilidade oferecido pelas cerimônias religiosas, e sucessivamente ao longo do oitocentos pela ópera e por espetá culos de tea tro, a pa rece ma is como uma a firma ção do espaço privado em dia de festa. Nessa acepção, o público emerge como possibilidade de constituição performativa do mundo.

Nas na rrativas de viajantes são constantes as reações de surpresa crítica diante da movimentação e da vozearia que predominavam no interior das igrejas. Os gestos, fartos e amplos, e as vozes altas são motivo de desagrado. E, desse modo, é destacado o lado paradoxal da religiosidade luso-brasileira, ma is expressa pelo componente de festividade do que de meditação. Assim, a ic onoclastia - a farta intimidade quase profana com as imagens religiosas - mostra um indício da artificialidade na experiência religiosa, o que, entre aqueles que eram originários de países protestantes, foi associada ao ca tolic ismo mediterrâneo.

A religiosidade entre brasileiros mais vinculada à exteriorida de da festa, em que o culto era ma is um espaç 0 de confra terniza ção, com uma extrema huma nização dos santos, e que fugia a uma concepção da religião mais de introjeção e sobriedade, foi criticada. o que esteve compreendido na concepção de interiorida de é um modo singular de relação consigo que inc luía formas específic as 
15 Ou ainda, em mais uma expressão do autor, o "observatório da vida alheia" (Ver em GONÇ ALVES, 1990, p. 154).

${ }^{16}$ LUC COCK, 1938 de introspeção da mensagem religiosa que resultava na abolição de elementos mágicos na relação com a divindade - exatamente o oposto da tradição católica portuguesa que abusa do colorido festivo, aproximando a religiosidade de suas formas pagãs de expressã $0 .{ }^{14}$

Os véus e mantilhas, lembrados no romance histórico Memórias de um Sargento de Milícias, de Manuel Antonio de Almeida, e que teve como cenário o Rio de Janeiro de Dom J oão VI, esc ondiam os rostos e os segred os femininos, compondo um costume luso-brasile iro que provocou ta mbém comentários varia dos de viajantes de ambos os sexos. $O$ uso do capote porhomense das mantilhase véus pelas mulheres à maneira árabe compunha uma marca dos diferentes segmentos socia is.

No livro de Murphy já indicado, uma gravura reproduz uma senhora no caminho da missa coberta por longo véu que envolve a cabeça e parte de seu corpo. Assim como os véus, desperta a inda a a tenção do viajante o ar arrogante das mulheres mais velhas, o que contrasta com a matreirice das moças de olhos vivazes e exp ressivos, com seus sapatos de cores alegres.

Ou seja, ocultar o corpo com panos garantia o a no nimato no território das ruas, percebido como a mea ça dor. Ma is uma vez, há uma concepção de público que o vincula à idéia de perigo. Daí, possivelmente, o recurso a osmantose véus enquanto preservadores de uma c erta idéia de individualidade que valoriza o nãoreconhecimento, protegendo o sujeito quando fora da a tmosfera protetora do domínio da casa. Como no exemplo do jilbab islâ mic 0 , o recurso à s mantilha s por mulheres, um costume remetido à colônia, garantiu o "ver sem ser visto", na feliz expressão de Manuel Antonio de Almeida ${ }^{15}$. Assim como as mantilhas, as rótulas nas casas asseguraram o a nonimato de quem olhava a rua.

O comerciante inglês John Luccock, que residiu no Brasil pordezanos(1808-1818), a ssoc iou o uso das gelosias nas casas do Rio de Janeiro, um costume abolido com a vinda da corte, à ausência de sociabilidade de seus moradores. ${ }^{16}$ Esse comentário realça, mais uma vez, um dos elementos da vida social que foi captada enquanto restrita aos interiores da casa, da Igreja ou do teatro, uma sociabilidade descrita freqüentemente como confusa, irregular, ora em decorrência da balbúrdia de vozes sobrepostas e do a buso da gestic ula ção, ora da ga lha rdia que apla inava as diferenças socia is.

Marianne Baillie, por sua vez, teceu comentários semelhantes sobre as portuguesas que conheceu. Baillie residiu dois anos e meio em Lisboa, no início da década de 1820, e public ou um livro composto de cartas destina das 
${ }^{17}$ BAILE, 1824, v. 2, p. 25.

à sua mãe. Baillie, da mesma maneira que James Murphy, refere-se à severidade da vida reclusa da mulher portuguesa, que quando no espaço da rua mantinha a distância ocultada por panos e pelo capote, um recurso partilhado por mulheres e homens. ${ }^{17}$

\section{2 - Indolência}

O encerramento em casa resultou em um outro problema moral, segundo a narrativa de viajantes. 0 território do doméstico emerge como o espaço da indolência, do corpo mole, da preguiça, da lascívia. Edaí o contraste com o mundo das ruas. Caem os panos, e essa reclusão que é percebida como confinadora se transforma em alimento de uma moral frouxa. Marianne Baille, em narrativa minuciosa e vigorosa, critica a displicência lânguida da rotina da mulherportuguesa. Nas entrelinhas do texto, está a a lusão à preguiça, a os há bitos do uso do corpo - sentadas de pemas cruzadas no chão, um sinal de desalinho -, à conversa de fofoca, à leitura "deturpa da" das Mil e uma Noites. Essa salusões ma nifestam normas e valores socia is que escapam aos cânones disciplina res de uma colocação do corpo já motiva da por dispositivos de autocontrole na percepção de uma ética do trabalho.

A impropriedade de brasileiros/portugueses manteve-se presente na preguiça, no nada fazer, indicando a valoração negativa do trabalho. A ausência de ocupação pareceu incompreensível a essa inglesa que veio de uma sociedade em que a étic a do trabalho passou a reger a ação e o domínio sobre o mundo. A ociosidade remetia a um distintivo do mundo a ristocrático em vias de esfacelamento.

Falando sobre educação, a completa negligência, mesmo entre as melhores fa mílias de Portugal, divertiria você: segundo rela tosque recebi de uma senhora, que nasceu e viveu aqui por muitos anos de sua vida, a maneira em que os jovens são educados é realmente desoladora, as mulheres nada fazem de manhã à noite, salvo restarem a olhar pelas janelas, perdendo-se languidamente numa atitude apática, com a cabeça a poiada na mão, e fa zend o comentá rios sa tíric os sobre cada um que passa. Quando a chegada da noite toma esse divertimento não mais possível, elas geralmente sentam, na companhia de suas empregadas, todas de pernas cruzadas sobre o chão, totalmente sem ocupação, enquanto sonolentamente escutam longas estórias [...]. Esses relatos usualmente consistem, ou da mais frívola fofoca, ou de contos deturpados, retirados das Noites Árabes. As empregadas estão

618 Estudos Feministas, Florianópolis, 13(3): 613-627, setembro-dezembro/2005 
18 BAILLE, 1824, v. 2, p. 65 . Ao longo do artigo, as traduções de citações de Marianne BAILLE, 1824, e A.P.D.G., 1826, são de responsabilidade da autora. freqüentemente saturadas de repetir esses relatos para suas patroas palermas [ênfa ses minhas]. ${ }^{18}$

O trecho acima revela um clima de cumplicidade no interior das casas que aproxima as mulheres da casa, senhoras e serviçais, e que é avaliado negativamente. A preguiça e a indolência a parecem nas entrelinhas do rela to de Baille como vestígios de luxúria e pusilanimidade, uma vez que subordinadas a uma percepção corporal descomposta. A referência às Mil e uma noites completa um quadro de torpor sensual que fornece à na rrativa uma sensação de incômodo nesse território ameaçador das sensações do corpo. Os peitos desnudos, a exuberância das formas dos corpos, elementos destacados pelos viajantes, foram associados à sexualidade transbordante, que exibida em público transforma um estar "à vonta de" corporal em falta de decoro. As narrativas sobre a preguiça feminina denotam uma percepção sobre o corpo que a nuncia um excesso em países tropicais.

A reclusão da mulher bra sileira/portuguesa é apontada como a origem de uma outra "má" formação de comportamento: a permanência ociosa nas janelas e balcõesdascasas, esp reitando o movimento da rua. Ema is, favoreceu um leque de práticas consideradas grotescas, como as do cafuné e da cata de piolhos.

Um outro comentário de um anônimo - assinado pelas inicia is A.P.D.G., talvez de um inglês que provavelmente viveu em Portugal, mas que conheceu ta mbém o Brasil nos primórdios do século XIX, quando da transferência da corte portuguesa para o Rio de Janeiro ressalta o hábito das mulheres portuguesas de mostra rem os peitos desnudos, causando estranheza aos costumes de estrang eira s/os. 0 a utor, embora contidamente, a ponta para a fartura das formas do corpo feminino, uma c a ra c terística do excesso da mulher portug uesa/b ra sileira.

Durante o pico do verão, a maioria das mulheres não usa nenhuma proteção que cubra os seios, os quais são conseqüentemente expostos à vista, mas, como é o hábito do país, não desperta a observação. Talvez, o hábito deste costume pode em alguma medida ser a tribuído, não meramente ao calor do clima mas a uma certa consciência de superioridade da forma neste particular, o que certa mente distingue as fêmeas portuguesas [ênfases minhas].19

Nas na rrativas de viajantes os costumes não só brasileiros como portugueses manifestam a ausência de decoro corporal. O viver luso-bra sileiro rea lç a va sem cessa $r$ um estilo de vida que pareceu remoto a o cotidiano desses andarilhos do mundo. Nessa a cepção, a exibição de partes 
do corpo, que as ma neiras do códig o civiliza do impunham que fossem cobertas, produziu sempre mal-estar e embaraço. Os corpos desnudos ou mesmo encobertos por inúmeros panos ind ic avam sem cessar o excesso.

Se acompanharmos as imagens que surgem desses relatos, nos deparamos com uma formulação moral que supõe uma idéia sobre a exibição do corpo ainda não associada a sensações de vergonha e pudor. Se a obscenidade é realçada, o é muito mais em decorrência do padrão de decoro de quem na rra do que daquele que é observado. Esses relatos destacam o contraste entre concepções distintas de produção de subjetividades. Entre viajantes desponta uma modelagem de subjetividade c entra da na a uto-reflexivida de e na interioriza ção, em que o domínio sobre si está associado a uma moral do corpo que implica sentimentos de pudor; a sua exposição restringe-se à ma is recôndita intimidade. Assim, a a usência de mecanismos de controle na exibição do corpo transforma brasileiros e portugueses em 'quase bárbaros'. O embaraço e o desconforto, tão presentes nas na rra tivas de viajantes, são traços, sintomas, do processo civilizador, como indica do por Norbert Elias para o caso europeu. Não se trata, entretanto, de sugerir que a concepção lusobrasileira sobre o corpo estivesse livre de constrang imentos. No entanto, é importante observarque o corpo não estava subordinado ao mesmo regime de interdições compreendido na mentalidade de viajantes.

Como indicado a cima, o falaralto, a a lgazarra das vá ria s vozes simultâ neas, a gestic ulação larga e exuberante durante a conversa eram sinais de comportamento que mostravam excesso, de algo que resvala para fora de um código de civilidade identifica do a o triunfo da educação sobre a rudeza, uma tipicidade de costumes identifica dos como luso-brasileiros.

A referência a uma gramática dos gestos entre enamoradosé notada na escrita de Maria Graham, quando do seu primeiro conta to com o Bra sil, em setembro de 1821, durante estada em Pernambuco. Essa prática da comunic a ção a tra vés dos gestos e dos olhos é a proximada dos costumes turcos e árabes:

Entre outrascoisas, a prendi pela observação, enquanto os ma is velhos das fa mília s esta va m entretid os nas ruas com os recém-chegados, que os jovens pemambucanos são tão destros no uso de sinais como os próprios amantes turcos, e que freqüentemente um namoro é mantido desta maneira, e termina em casamento sem que as partes tenham sequer ouvido

20 GRAHAM, 1990 , p. 142. as respec tivas vozes [ênfa ses minhas].20

620 Estudos Feministas, Florianópolis, 13(3): 613-627, setembro-dezembro/2005 
${ }^{21}$ UNDLEY, 1805, p. 177.

22 GRAHAM, 1990, p. 168.
Na a cepção de viajantes, a precisã o moral do corpo exige o domínio sobre os gestos, o uso correto do vestuá rio de forma a exibir o físico como um templo sagrado da individualidade, a extemalização do 'eu verdadeiro'. Essa ação moral sobre o corpo delineia-se como condição da constituição do sujeito. Portanto, é uma divergência nas a cepções sobre a formação de indivíduos que desponta na denúncia do excesso, recorrente nas interpretações de viajantes sobre o Brasil, o que foi usualmente integrado a um cená rio de barbá rie e incivilida de, já a cima sugerido.

Embora a sexualidade seja raramente mencionada nos diferentes relatos de mulheres viajantes, a temática impregna a escrita em suas descrições sobre o desalinho das mulheres brancas e o vigor físico de escravas e escravos. Na narrativa de Maria Graham a exibição de partes do corpo, não devidamente protegidas por a rma duras, como corpetes e espartilhos, é poluidora. Enas entrelinhas desponta um enorme desconforto pelo aspecto voluptuoso do físic o feminino. Se na escrita das viajantes a sensualidade de mulheres é sub-repticiamente mencionada, em alguns relatos masculinos ela é claramente indicada. 0 inglês Thomas Lindley, que esteve no Brasil no início do século XIX, desc reve a maneira pouco pudica de as mulheres exibirem o peito e revela o seu desagrado intolerante com a pele escura, uma visão "desagradável", que "violenta a delicadeza feminina". ${ }^{21}$

Assim como Lindley, também Maria Graham, em relato durante sua permanência na Bahia, descreve mulheres com corpos indecentemente desalinha dos, cujas vestimentas, na a usência da exibiçã o do ima cula do branco nas roupa síntimas, a presentam um a spec to sujo. O costume de mulheres em suas casas vestirem-se displic entemente, com as formas visíve is do corpo, sem o suporte de um espartilho, e a ausência de qualquer formalidade constituíam indicadores de contaminação e sujeira. A narrativa de Graham registra a sua "repugnância" com o jeito desleixado das brasileiras:

Como nã o usa m nem coletes, nem espartilhos, o corpo toma-se quase indecentemente desalinhado, logo após a primeira juventude; e isto é tanto mais repugnante quanto elas se vestem de modo muito ligeiro, não usam lenços ao pescoço e raramente os vestidos têm qualquer manga. Depois, neste clima quente, é desagradável ver escuros algodões e outros tecidos, sem roupa branca, diretamente sobre a pele, o cabelo preto mal penteado e desgrenhado, amarrado inconvenientemente, ou, a inda pior, em papelotes, e a pessoa toda com a aparência de não ter tomado banho [ênfa ses minhas]. ${ }^{22}$ 
${ }^{23}$ Roger CHARTIER, 1991, p. 113.

${ }^{24}$ O século XIX acompanhou ainda 0 crescimento de mulheres escritoras, como é assinalado por Peter Gay para o caso da Ingla terra: "Artigos, poemas, dramas, romances, livros de viagem e de auto-ajuda eram mostras de um talento arduamente adquirido e precariamente gozado. Nos primeiros anos do reinado de Vitória, a mulher autora era uma figura familiar, embora não universalmente amada, uma protagonista na grande redefinição de papéis que marcou a era" (GAY, 1995, p. 331).
A falta de pudoratribuída à mulher, que foi remetida para a dimensão do vulgar, colide com uma outra imagem que os viajantes difundiram, a da reclusão da mulher bra sileira/portuguesa dos setores médios e altos, formando quase um folclore sobre esse universo feminino, como foi mencionado acima. Por um lado, temos a imagem de confinamento da mulher que é reportada na letra de viajantes a um código moral severo de controle. Por outro, relatam-se cenas de mulheres que foram olhadas com repugnância pela exibição de seuscorpose consideradas sem decoro. Esses dois perfis que aparecem como descontínuos, apontam para uma manifestação de impressões ambíguas mas complementares. O texto de viajantes revela diferenças entre suas percepções e a de brasileiros e portugueses sobre a sociabilidade e os usos do corpo. Dessa maneira, tudo que é estra nho e que produz embaraço a viajantes é remetido para esse excesso tanto do recato como da exibição.

\section{3 - Educação}

A cultura da escrita foi um dos traços da modemidade burguesa que dema rcaram uma relação de intimida de entre texto e leitore que marcaram a separação entre a vida privada e a pública..$^{23}$ Nessa perspectiva, lere esc rever foram instrumentos que liberta ra $m$ a humanida de das amarras de um passado percebido como de "obscurantismo" e "barbárie". O processo civilizatório impunha um progressivo movimento de isolamento e interiorização do indivíduo. O livro era o exemplo da possibilidade de riqueza individual que o hábito de leitura desvelava, num mergulho do sujeito num prazer solitário, promotor do autoconhecimento e da consciência de si. No Ocidente, a o longo do oitocentos, o crescimento do merca do livreiro a pontava para a disseminação da leitura, atingindo públicos maiores, e promovia a sensação em cada leitor de uma fruição pessoal e única, reveladora da sua onip otência no teritório da intimidade. Atra vés da leitura abria-se um inesgotável mundo de aventuras e descobertas. E, nesse mercado, o público feminino representou um segmento em intensa expansão. ${ }^{24}$ Assim, a primeira reação de viajantes, exemplos da missão civilizatória, à falta do hábito de leitura foi de espanto e crítica.

A inexistência de livros na maioria das casas que Maria Graham visitou é por ela indicada como um dos aspectos que confirmam a pouca atenção oferecida à instrução na sociedade brasileira. Poucas eram as residências que possuíam uma estante com livros, quando 
25 BAILLE, 1824, v. 2, p. 65.

${ }^{26}$ Wanderley PINHO, 1970, p. 21. muito exib iam um exemplar da Bíblia. Mesmo as casas que exibiam livros, em geral parte de uma pequena biblioteca especializada em direito ou medicina, não os transforma vam em algo de uso cotidiano. Uma a valia ção semelhante à de Graham é realizada por Marianne Baille sobre Portugal. Esta comenta a completa negligência com a educação, mesmo entre as "melhores famílias" de Portugal, qualificando de "triste" o cenário de formação dos jovens, especialmente de mulheres. ${ }^{25}$

Maria Graham faz menção, quando já de sua segunda visita ao Rio de Janeiro, após um ano de residência no Chile em 1823, à primeira biblioteca que conheceu em terras brasileiras. A viajante indica em tom de surpresa e encantamento as transformações nos comportamentos da elite na cidade corte. A descrição da cena ocorre em casa de um desembargador da Relação do Rio de Janeiro e deputado pela Bahia na Assembléia Constituinte, conselheiro Luís] osé de Carvalho e Melo, futuro primeiro visc onde da Cachoeira. ${ }^{26}$ Maria se toma ra a miga de sua filha Dona Carlota, como a chama, e foi essa amiga que a a presentou a autoresportugueses - começa va então a falar o português. Em especial, lembra dos versos, que a fascinaram, de Antônio Dinis da Cruz e Silva, um dos fundadores da Arcádia Lusitana em 1756, admirador de Pombal. Antônio Dinis da Cruze Silva esteve no Bra sil, tendo falecido no Rio de Janeiro. ${ }^{27}$ Sobre Dona Carlota, Graham tece enormes elogios. E é em casa do conselheiro que conhece mulheres portuguesas/brasileiras que propiciam momentos de prazer na conversa:

A filha do casal, D. Carlota, distingue-se aqui pelo talento e cultura acima de suas companheiras. Fala e escreve francês bem e fez progressos não pequenos em inglês. Conhece a literatura de sua terra, desenha corretamente, canta com gosto e dança graciosamente. Várias de suas primas e tias falam francês correntemente, de modo que tive o prazer de conversar livremente com elas e receber boa cópia de informações sobre assuntos que só interessam a mulheres. ${ }^{28}$

É este o perfil da educação feminina - domínio de líng ua s estrang eiras, conhec imentos de litera tura na ciona I, desenho, canto e dança - valoriza do por Maria Graham e com o qual está fa milia riza da. Seu comentá rio é tecido a o longo do rela to sobre a festa de aniversário de Ana Vidal Carneiro da Costa, mulher do conselheiro Luis José. A narrativa elogiosa é, entretanto, interrompida pela introdução de observações de um conterrâneo seu que lembra a "imoralidade" que em geral marca a sociedade brasileira. 0 ing lês reporta-se às maneiras que considera 
${ }^{29}$ GRAHAM, 1990, p. 271-272.

\footnotetext{
${ }^{30}$ GRAHAM, 1990, p. 175-176.
}

dissimuladas de brasileiros-portugueses, que acredita revela rem um caráter viciado, em muito estimula do pela proximid a de da escra vidão. A simula ção é um meca nismo do comportamento de brasileiros-portugueses que é criticado, uma vezque procura escondero que as pessoas verdadeiramente são, encobrindo uma essência que, segundo a percepção desse observador em trânsito, permanece rude e simplória. O recurso do fingimento, presente na linguagem dos olhos e dos bilhetes que deslizam por entre as mãos, se sobrepunha ao léxico da civilidade. O artifício que compõe um mecanismo de operação da sociabilidade de corte é traduzido como dissimulação e fing imento.

Felizmente ele avançou dema is e ousou a postar (que é a maneira que um inglês tem de afimar) que havia naquela sala pelo menos dez senhoras providas do bilhete que escorregariam na mão de seus galãs, e que tanto as casadas como as solteira seram a mesma coisa. [...] Olhou lentamente em tomo da sala e comecei a tremer, mas a final ele disse: "Não, a qui não; mas não nego que tais coisas se passam no Rio. [...] Lembre-se de que entre nós, além da mãe de família, há uma ama, ou uma govemante, ou mesmo uma camareira para cada moça, que deve serbem educada, de bom caráter e de boa moral. Tudo isso são freios para o comportamento e forma uma proteção só inferiorà da mãe. Mas no Brasil os serviçais são escravos, e por conseguinte inimigos natura is de seus senhores, dispostos a decepcioná-los e desejosos disso, e de assistir à comupção de suas famílias. Esta exposição abriu-me os olhos para vários aspectos para os quais a té agora minha atenção havia perpassado igua Imente. ${ }^{29}$

Apesar da europeização da aparência extema que essas mulheres apresentavam, Maria Graham sublinha a extrema artificialidade do comportamento quando as compara às suas conterrâneas presentes na mesma recepção que, embora sejam por ela percebidas como de "segunda categoria", fazem melhor figura.

As inglesas, porém, ainda que quase de segunda categoria, ou mesmo da nobreza colonial, a rrebata ram o prêmio de beleza e da graça, porque afinal os vestuários, ainda que elegantes, quando não são usa dos ha bitualmente, nã o fa zem senão embaraçare estorvar os movimentos espontâneos e, como nota Mademoiselle Clairon, "para poder representar de fidalga em público, é preciso que a mulher o seja na vida privada" [ênfases minhas]. ${ }^{30}$

624 Estudos Feministas, Florianópolis, 13(3): 613-627, setembro-dezembro/2005 
${ }^{31}$ GONÇ ALVES, 2002.

Mais uma vez, o trecho acima aguça a descontinuidade entre a casa e o espaço da rua na apreensão que viajantes apresentam da vida brasileira. Se para viajantes o sujeito deve agir de forma similar nos espaços da casa e em público, nos hábitos que são retratados de brasileiros é reforçada a discrepância, em que o domínio público se constitui como o território do artifíc io, onde são incorpora dos os pa péis id entific a dos com a boa educação. Nessas situa ções o corpo "desa linha do" é contido por espartilhos, numa elegância à européia, ou seja, na ordem burguesa os indivíd uos tra nsita m em públic o como sujeitos privados. Não se recorre a duas lógicas de comportamento, uma da casa, outra da rua, como se a figura para a sociedade brasileira, seguindo o relato das viajantes.

Em Graham, como em vários outros relatos de viajantes, está presente a dissonância entre o mundo europeiza do da civiliza ção e os trópicos do excesso não contido, não educado; descompasso entre os planos extemo e intemo - a revolução realizada na aparência, roupas, penteados, não era ainda internalizada.

Ma is uma vez, a idéia de falso presente no recurso a o artifício guamece a cena com ares de comédia, de uma sociabilidade que brinca de parecer européia e c iviliza da. Asinglesas, mesmo que de "segunda categoria", são detentoras, entretanto, de uma autenticidade que escapa às brasileiras, que exibem em público uma a parência postiça. A compreensão da conduta social como puro artifíc io retoma uma modalidade de operação da sociedade de corte dos antigos regimes. 0 artifício remete para esse ideal do fidalgo ibérico e se aproxima do comportamento do mandarim chinês pela correção ritualístic a. ${ }^{31}$ Esse formalismo da conduta fornece essa impressão, realçada por viajantes, da ausência de interioridade, de uma superficialidade de boas maneiras que indicava a falta de um centro condutor do controle sobre si. Na verdade, segundo viajantes, se há algum centro, ele é oco e vazio.

\section{Referências bibliográficas}

A.P.D.G. Sketches of Portuguese Life, Manners, Costume, and Character. London: B. Whitta ker, 1826.

ARIĖS, Philippe. "Por uma história da vida privada". In: ARIĖS, Philippe; CHARTIER, Roger. História da vida privada: da Renascença a o Século das Luzes. São Paulo: Companhia das Letras, 1991. v. 3. p. 7-19.

BAIШE, Maria nne. Lisb on in the Years 1821, 1822, and 1823. Lond on: J ohn Murra y, Albema rleStreet, 1824. 2 v. 
BAKHTIN, Mikhail. A cultura popular na Idade Média e no Renascimento: o contexto de François Rabelais. São Paulo: Hucitec; Bra sília: Edunb, 1999.

BENJ AMIN, Walter. "O narrador: considerações sobre a obra de Nikolai Leskov". Magia e técnica, arte e política: obras escolhidas. São Paulo: Brasiliense, 1993. v. 1. p. 197221.

CHARTIER, Roger. "As práticas da escrita". In: ARIĖS, Philippe; DUBY, Georges. História da vida privada: da Renascença a o Século das Luzes. São Paulo: Companhia das Letras, 1991. v. 3. p. 113-161.

DIAS, Maria Odila Leite da Silva. Quotidiano e poder em São Paulo no século XIX. São Paulo: Brasiliense, 1984.

ELIAS, Norbert. O processo civilizador: uma história dos costumes. Rio de Janeiro: Jorge Zahar, 1990.

GAY, Peter. O cultivo do ódio. São Paulo: Companhia das Letras, 1995.

GONÇALVES, Marga reth de Almeida. Expostos à miseric óridia. 1990. Disserta ção (Mestra do em Sociologia) - Instituto Universitá rio de Pesquisas do Rio de Janeiro.

- Império da fé: misticismo e narrativas do feminino em Goa e no Rio de Janeiro (séculos XVII e XVIII). 2002. Tese (Doutorado em Sociologia) - Instituto Universitário de Pesquisas do Rio de Janeiro.

"Civiliza ção e artifíc io: a s viajantes e o Bra sil oitocentista". Fragmentos de Cultura, Goiânia, v. 13, n. especial, 2003. p. 279-297.

GRAHAM, Maria. Diário de uma viagem ao Brasil e de uma estada nesse país durante parte dos anos de 1821, 1822 e 1823. São Paulo: Companhia Ed itora Na cional, 1990.

LEITE, Miriam Lifchitz Moreira. A mulher. Rio de J a neiro (1800-1850). Sã o Pa ulo: Fundação Carlos Chagas, 1979. Mimeo.

LIMA, Luiz Costa Lima. O controle do imaginário: razão e imaginação nos tempos modernos. 2. ed. Rio de Ja neiro: Forense Universitária, 1989.

LINDLEY, Thomas. Narrative of a Voyage to Brazil. Londres: J. J ohnson, 1805.

LITVAK, Lily. El ajedrez de estrellas: crônic as de viajeros españoles del sig lo XIX por países exótic os (1800-1913). Barcelona: Ed itorial Laia, 1987.

LUCCOCK, John. Notas sobre o Rio de J a neiro e partes meridionais do Brasil. São Paulo: Livra ria Martins Editora, 1938.

MARTINS, Luciana de Lima. O Rio de J aneiro dos viajantes: o olhar britânico (1800-1850). Rio de Janeiro: Jorge Zahar, 2001.

MURPHY, James. Travels in Portugal through the Provinces of entre Douro, Minho, Beira, Estremadura and Além-Tejo. London: A. Strahan and T. Cadell Jun. and W. Davies, 1795.

PINHO, Wanderley. Sa lões e da mas do Segundo Reina do. Sã o Paulo: Livra ria Martins Editora, 1970.

PRATT, Mary. Os olhos do império: rela tos de viagem e transcultura ção. São Pa ulo: EDUSC, 1999.

ROUANET, Maria Helena. Eternamente em berço esplêndido: a fundação de uma literatura nacional. São Paulo: Siciliano, 1991.

SAMARA, Eni de Mesquita. A família brasileira. 4. ed. São Pa ulo: Brasiliense, 1998.

SARAIVA, Antonio J osé; LOPES, Oscar. História da Literatura Portuguesa. 7. ed. Porto: Porto Ed itora, 1955.

SÜSSEKIND, Flora. O Brasil não é longe da qui: o narra dor e a via gem. Sã o Paulo: Companhia das Letras, 1990. 
[Recebido em setembro de 2005 e aceito para publicação em novembro de 2005]

\begin{abstract}
Artifice and Excess: Travel Narratives and the Representation of Women in Portugal and Brazil

Abstract: This article analyses the images of Brazilian and Portuguese women in the reports of English travelers who visited Portugal and Brazil in the final years of the $18^{\text {th }}$ century and early decades of the $19^{\text {th }}$ century. We seek to investigate the way in which a moral register based on bourgeois values influenced these tra velers' views and interfered in their descriptions of the LusoBrazilian universe. The connection they made between the 'civilized' European world and the regions which were peripheral to the processes of bourgeois capitalism generally involved a double movement of confrontation and negotiation between culturally distinct values and worldviews. Thus, their travel narratives reveal a space of constant negotiation of feelings and perceptions about themselves and the natives.

KeyWords: travel books, gender, private/public, education.
\end{abstract}

